\title{
Effect of roughness shape on heat transfer and flow friction characteristics of solar air heater with roughened absorber plate
}

\author{
A. Chaube ${ }^{1}$, P. K. Sahoo ${ }^{2}$ \& S. C. Solanki ${ }^{2}$ \\ ${ }^{1}$ GEC, Jabalpur, India \\ ${ }^{2}$ IIT Roorkee, India
}

\begin{abstract}
A 2-D computational analysis is carried out to assess the comparative performance of the absorber plate of a solar air heater with different roughness elements using commercial software package Fluent 6.1. The assessment is based on heat transfer enhancement with minimum pressure penalty. Ten different rib shapes (viz. Rectangular, Square, Chamfered, Triangular, Semicircle etc) are investigated at the Reynolds number range from about 3000-20000, in which solar air heaters normally operate. The SST $\mathrm{k} \omega$ turbulence model is selected by comparing the predictions of different turbulence models with experimental results available in the literature. Using the selected turbulence model a computational analysis is carried out to predict the heat transfer performance and flow friction characteristics of absorber plates with 10 different rib roughness elements. The analysis is carried out for both the flow regimes i.e. transitional flow regime $\left(5 \leq \mathrm{e}^{+} \leq 70\right)$ and fully rough regime $\left(\mathrm{e}^{+} \geq 70\right)$.

Keywords: turbulence, roughness Reynolds number, aspect ratio, friction factor, heat transfer coefficient, Nusselt number, chamfer angle, pitch etc.
\end{abstract}

\section{Introduction}

Artificial roughness up to laminar sub-layer to enhance heat transfer coefficient is used in various applications like gas turbine blade cooling channels, heat exchangers, nuclear reactors and solar air heaters. A number of experimental studies $[1,2]$ in this area have been carried out but very few attempts of numerical investigation have been made so far due to complexity of flow pattern and computational limitations. In the present work, an attempt is made to predict 
numerically, the details of both the velocity and temperature fields responsible for heat transfer enhancement. The presence of rib may enhance heat transfer because of interruption of the viscous sub layer, which yields flow turbulence, separation and reattachment leading to a higher heat transfer coefficient. The enhancement of heat transfer by flow separation and reattachment caused by ribs is significantly higher compared to that by the increased heat transfer area due to ribs (fin-effect) [3]. The heat transfer measurements results for two different steps, $\mathrm{p} / \mathrm{e}=14$ and $\mathrm{p} / \mathrm{e}=8$, indicate the importance of roughness geometry [4]. Liou et al. [6] have performed both the numerical analysis and experimental study to investigate the heat transfer and fluid flow behavior in a rectangular channel flow with stream wise periodic ribs mounted on one of the principal walls. They have concluded that the flow acceleration and the turbulence intensity are two major factors that influence the heat transfer coefficient. The combined effect is found to be optimum for the pitch to rib height ratio equal to 10 , which results in the maximum value of average heat transfer coefficient. Rau et al. [5] experimentally found optimum pitch to rib height ratio to be equal to 9 . Hence these investigations reveal that not only the rib geometry but also its geometrical arrangement play vital role in enhancing the heat transfer coefficient. Karwa [7] has reported an experimental investigation for the same configuration for the Reynolds number range of 4000-16000. Tanda [9] has reported experimental investigation of heat transfer in a rectangular channel with transverse and $\mathrm{V}$-shaped broken ribs using liquid crystal thermography. He concluded that features of the inter-rib distributions of the heat transfer coefficient are strongly related to rib shape and geometry; a relative maximum is typically attained down stream of each rib for continuous transverse ribs (due to flow reattachment). The main aim of the present analysis is to investigate the flow and heat transfer characteristics of a 2 dimensional rib roughened rectangular duct with only one principal (broad) wall subjected to uniform heat flux by making use of computer simulation. The ribs are provided only on the heated wall. The other three walls are smooth (without ribs) and insulated. Such a case is encountered in solar air heaters with artificially roughened absorber plate.

\section{Solution domain}

The solution domain shown in Fig. 1 has been selected as per the experimental details given by Karwa [7]. A rectangular duct with the duct height(H) of $40 \mathrm{~mm}$, rib height (e) of $3.4 \mathrm{~mm}$, rib width of $5.8 \mathrm{~mm}$ and pitch (p) of $34 \mathrm{~mm}$ has been taken for analysis. The uniform heat flux of $4 \mathrm{~kW} / \mathrm{m}^{2}$ is given on ribbed surface. A 2-D CFD analysis of heat transfer and fluid flow through a high aspect ratio (7.5) rectangular duct with transverse ribs provided on a broad, heated wall and other three walls smooth and insulated, is carried out using Fluent 6.1 software. A non-uniform rectangular mesh with grid adoption for $\mathrm{y}+=1$ at adjacent wall region is applied as shown in Fig. 2. Similar analysis is carried out for a smooth duct of same dimensions for similar range of Reynolds number 3000 to 15000 to 
find out the ratio of Stanton number for ribbed duct and smooth duct as experimentally determined by Karwa [7].

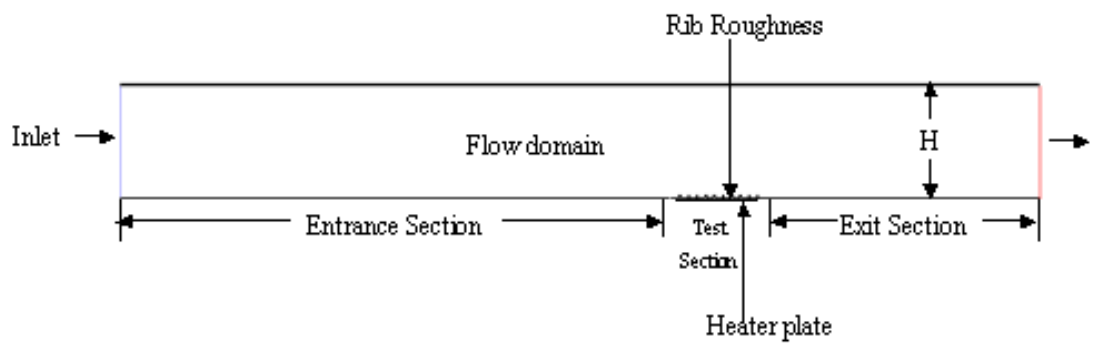

Figure 1: Duct geometry and solution domain as per experimental details of Karwa [7].

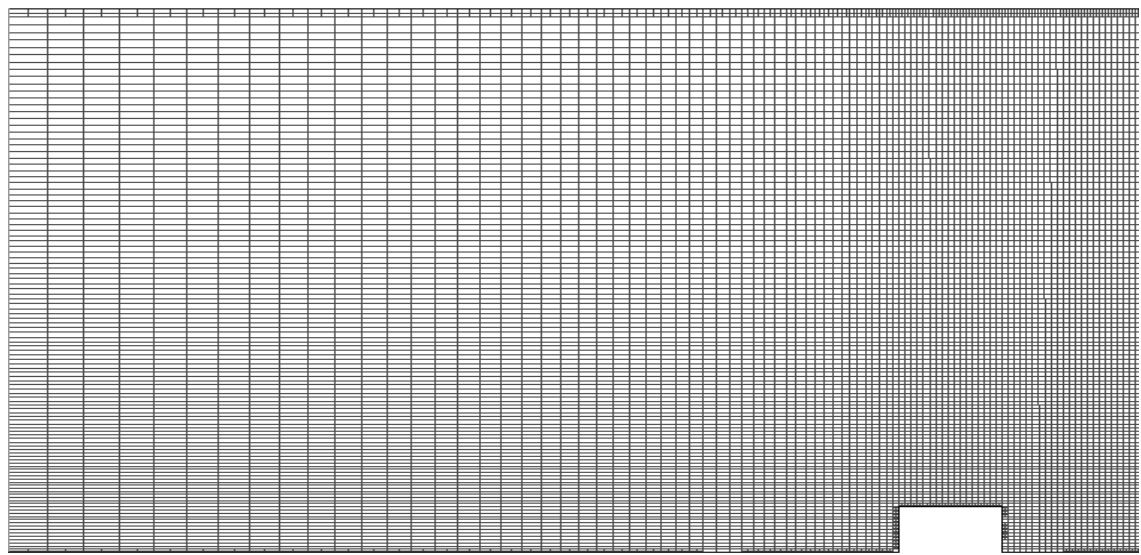

Figure 2: Rectangular mesh with grid adoption for $\mathrm{y}^{+=1}$ at top and bottom wall.

\subsection{Selection of turbulence model}

To select the turbulence model, the previous experimental study is simulated using different low Reynolds number models such as Standard $\mathrm{k} \omega$ model, Renormalization-group $\mathrm{k} \varepsilon$ model, Realizable $\mathrm{k} \varepsilon$ model and Shear stress transport $\mathrm{k} \omega$ model. The results of different models are compared with experimental results. The shear stress transport $\mathrm{k} \omega$ model is selected on the basis of its closer results to the experimental results as shown in Fig. 3.

\subsection{Thermo hydraulic assessment of different roughness elements}

After finding out satisfactory simulation capability of the SST k $\omega$ turbulence model, the performance of different rib shapes as shown in Fig.4 have been 
assessed. The similar flow domain used for the predictions is as shown in Fig.1. The other parameters used are as follows (for transitionally rough flow regime):

$\begin{array}{llll}\text { Reynolds Number } & =2900 \text { to } & \mathrm{e}^{+} \text {Range } & =7 \text { to } 84 \\ \text { Range } & 19500 & & =10 \mathrm{~mm} \\ \begin{array}{ll}\text { Duct height }(\mathrm{H}) \\ \text { Inlet length }\end{array} & =20 \mathrm{~mm} & \text { Pitch }(\mathrm{p}) & =1 \mathrm{~mm} \\ \text { Length of test section } & =121 \mathrm{~mm} & \begin{array}{l}\text { Rib Height (e) } \\ \text { Aspect Ratio of Duct }\end{array} & =5 \\ \text { Outlet length } & =115 \mathrm{~mm} & \text { (AR) } & \\ & & & \end{array}$

\subsection{For fully rough flow regime}

$\mathrm{e}^{+}$Range $=35$ to $400 \quad$ Rib Height $\quad=3 \mathrm{~mm}$

\section{Turbulence Model Selection}

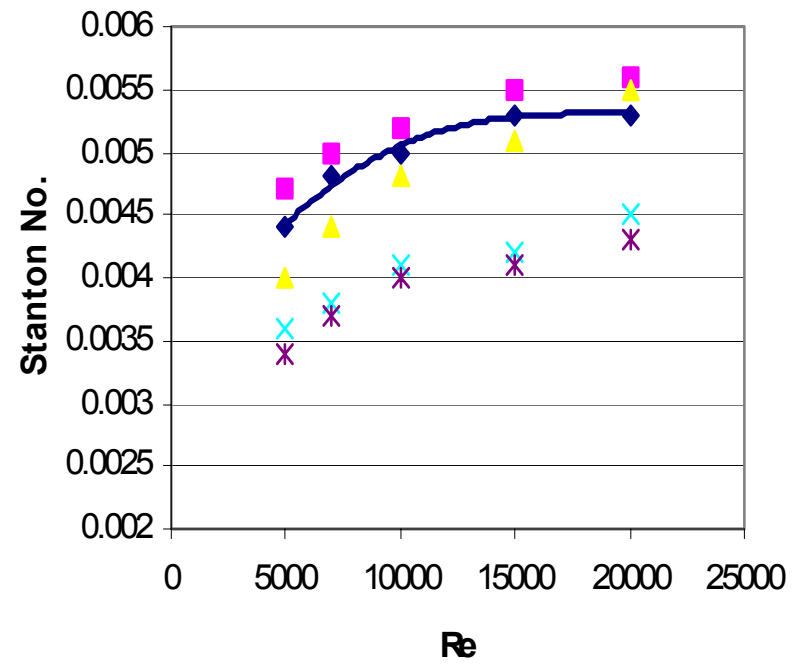

\begin{tabular}{|c|c|}
\hline - Experimental Results[7] & Shear Stress Transpot kw \\
\hline 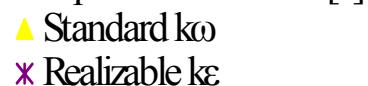 & $\times$ Renormalization-group $\mathrm{k} \varepsilon$ \\
\hline
\end{tabular}

Figure 3: Comparison between experimental and computational predictions from different low Re turbulence models.

\subsection{Boundary conditions}

The following boundary conditions are given through the boundary conditions panel:

(i) Velocity at inlet

(ii) Turbulence intensity at inlet (20\% taken from literature) 
(iii) Hydraulic diameter of duct

(iv) Out let pressure (Atmospheric pressure)

(v) Constant heat flux on broad bottom surface of test section

(vi) No heat transfer from other walls of the duct.
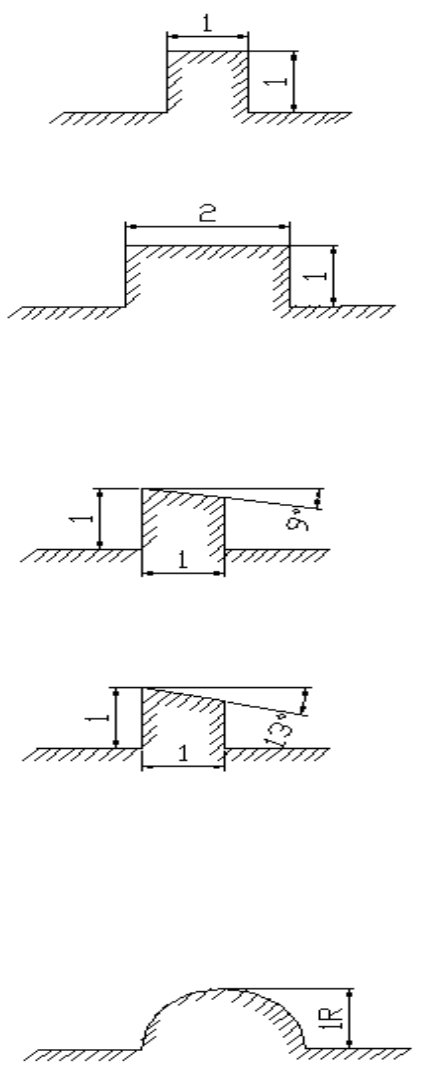

Figure 4: Different roughness elements under investigation.

\section{Results and discussion}

The comparative performance of different roughness elements are obtained on the basis of heat transfer enhancement at constant pumping power requirement or performance index as described below:

$$
\eta=\frac{S t}{S t_{o}} /\left(\frac{f}{f_{o}}\right)^{1 / 3}
$$




\section{Performance index Vs Re in Transitionally Rough Flow Regime}

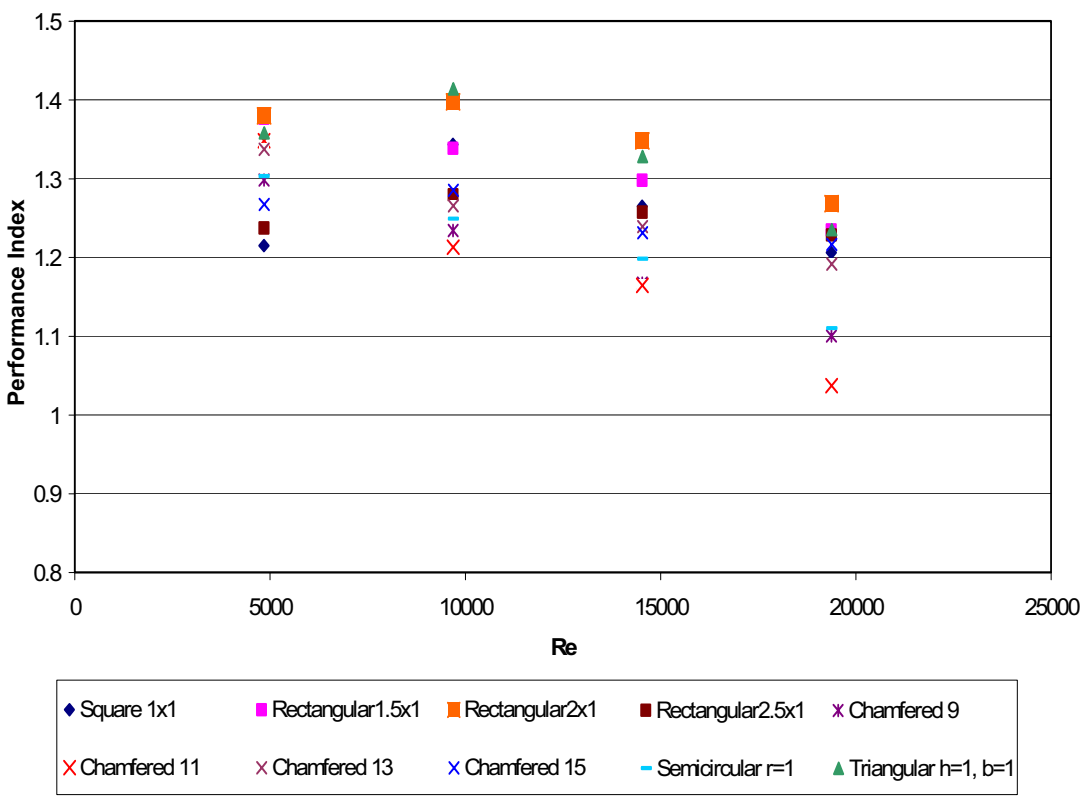

Figure 5: Variation of heat transfer enhancement for constant pumping power requirement with Reynolds number.

Performance index Vs Re in Fully Rough Regime

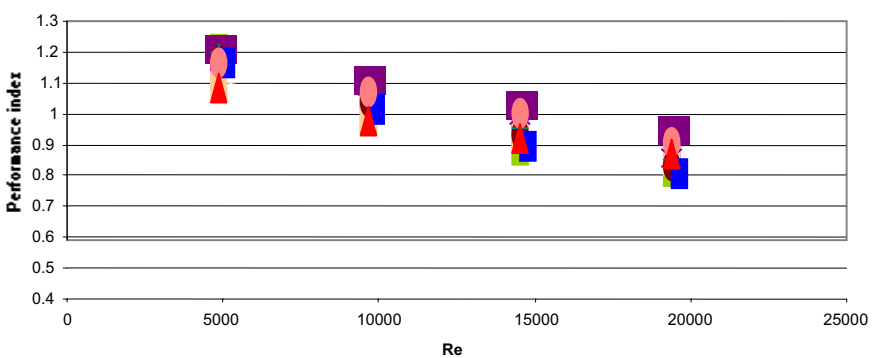

\begin{tabular}{|c|c|c|c|c|}
\hline 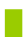 & Rectangular $2 \times 3$ & Square $3 \times 3$ & Rectangular $4 \times 3$ & Rectangular $5 \times 3$ \\
\hline * & Chamfered 11 & Chamfered 13 & $+\quad$ Chamfered 15 & Chamfered 17 \\
\hline C & Semicircular $r=3$ & Triangular $\mathrm{h}=3$ & & \\
\hline
\end{tabular}

Figure 6: Variation of heat transfer enhancement at constant pumping power with Reynolds number. 
The comparison of the performance by different rib geometries for equal pumping power would be more useful for engineering applications. The performances of different roughness elements on the basis of equal pumping power for transitionally rough flow regime and fully rough flow regime are shown in Figs. 5 and 6 respectively. In transitionally rough flow a substantial enhancement in heat transfer is found along with increase in friction factor, but in fully rough flow a marginal enhancement in heat transfer over that in the transitionally rough flow is found with sharp increase (more than double in comparison to transitionally rough flow regime) in friction factor. Therefore a low value of performance index is found in fully rough flow regime in comparison to transitionally rough flow regime.

In the transitional flow regime rectangular rib of $1 \mathrm{~mm}$ height and $2 \mathrm{~mm}$ width shows best performance among all rib shapes under investigation. Among the rest of ribs, the triangular rib of $1 \mathrm{~mm}$ height and $1 \mathrm{~mm}$ base gave the best performance.

In the fully rough flow regime rectangular rib of $3 \mathrm{~mm}$ height and $4 \mathrm{~mm}$ width is found as best performer under constant pumping power conditions. Although the square rib $(3 \times 3)$ gives the best heat transfer characteristics for constant mass flow rate condition.

The effects of various flow and roughness parameters on heat transfer and friction characteristics for flow of air in a rectangular duct of aspect ratio 5 under the present investigation are being discussed below:

\subsection{Variation of Nusselt number with Reynolds number}

In all cases Nusselt number increases with the increase of Reynolds number. The rate of increase of Nusselt number with Reynolds number is substantially higher in roughed duct in comparison to that of in smooth duct of similar dimension. The effect of roughness on variation of Nusselt number with the Reynolds number may be explained as under:

At low Reynolds number in transitionally rough flow the roughened surface Nusselt numbers are nearly those of smooth surfaces. It is because the roughness elements lie within the laminar sub layer, which is the major component of the heat transfer resistance. As the Reynolds number increases, the roughness elements begin to project beyond the laminar sub layer because the boundary layer thickness decreases with an increase in Reynolds number. This reduction in boundary layer thickness increases the heat transfer rate. In addition to this, there is local contribution to the heat removal by the vortices originated from the roughness element. Thus the Nusselt number curve deviate from the smooth duct turbulent Nusselt number curve. When the Reynolds number further increases, the roughness elements project deeper in to the turbulent region. Finally, with the increase of Reynolds number, the thickness of laminar sub layer becomes very small and energy loss due to the vortices now attains a constant value and is independent of viscous effect. 


\subsection{Variation of friction factor with Reynolds number}

The shedding of vortices also causes additional loss of energy resulting in increased friction factor. Thus the friction factor curves deviate from the smooth duct friction factor curve.

Except semicircular rib, in all the cases friction factor increases with increase of Reynolds number in both the flow regimes. In almost all the cases friction factor becomes independent of Reynolds number at high flow rates. The Reynolds number corresponding to the start of the region of independence of friction factor is termed as critical Reynolds number.

\subsection{Effect of rib width}

In the transitionally rough flow regime increasing the width of square rib enhancement of heat transfer and reduction in friction factor is observed. Where as in fully rough flow regime also the best performance index is found for $4 \mathrm{x} 3$ rib. Hence for every flow condition there is an optimum w/e ratio. In case of transitionally rough flow $2 \times 1$ rib gives the best performance index. The further increase in width gives negligible or adverse effect.

\subsection{Effect of chamfer angle}

It is observed that both the flow regimes, transitionally rough and fully rough, the effect of chamfer angle in enhancement of heat transfer is very small in comparison to the enhancement of friction factor. That is why chamfered rib roughness did not exhibit the comparable performance index with other types of roughness.

\section{Conclusions}

The following conclusions are drawn from the present analysis:

- The Shear Stress Transport k $\omega$ turbulence model predicted very close results to the experimental results, which yields confidence in the predictions done by CFD analysis in the present study.

- In transitionally rough flow a substantial enhancement in heat transfer is found along with increase in friction factor, but in fully rough flow a marginal enhancement in heat transfer over that in the transitionally rough flow is found with sharp increase (more than double in comparison to transitionally rough flow regime) in friction factor.

- The reattachment point and point of maximum heat transfer coincide, which shows the great influence of reattachment of flow on convective heat transfer coefficient.

- The results show that in rectangular ribs, there is an optimum width of rib, at which it gives maximum heat transfer with minimum pressure drop penalty. 
- In continuous transverse ribs chamfering is not much effective because although it gives small enhancement in heat transfer but at the cost of steep rise in friction factor.

- The thermohyraulic analysis for constant pumping power shows that rectangular rib (1mm x $2 \mathrm{~mm}$ ) gives the best performance in comparison to other shapes under consideration.

\section{References}

[1] Muluwork, K.B., Solanki, S.C., and Saini, J.S., 2000, “ Study of heat transfer and friction in solar air heaters roughened with staggered discrete ribs," Proc. $4^{\text {th }}$ ISHMT- ASME Heat and Mass Transfer Conf., Pune, India, pp.391-398.

[2] Karwa, R., Solanki, S.C., and Saini, J.S., 2001, “ Thermo-hydraulic performance of solar air-heaters having integral chamfered rib roughness on absorber plates," Energy 26, 161-176 (2001).

[3] Lee, C.K., and Abdel-Moneim, S.A., 2001, “ Computational Analysis of Heat Transfer in Turbulent Flow Past a Horizontal Surface with 2-D Ribs," Int. Comm. Heat Mass Transfer, Vol. 28 No.2, pp. 161-170.

[4] Slanciauskas, A., 2001, “ Two friendly rules for the turbulent heat transfer enhancement" Int. Jr. of Heat and Mass transfer 44, 2155-2161.

[5] Rau, G., Cakan, M., Moeller, D., and Arts, T., 1998, "The Effect of Periodic Ribs on the Local Aerodynamic and Heat Transfer Performance of a Straight Cooling Channel," ASME Vol. 120, pp. 368-375.

[6] Tong-Miin Liou, Jenn-Jiang Hwang and Shih-Hui Chen, "Simulation and measurement of enhanced turbulent heat transfer in a channel with periodic ribs on one principal wall" Int. Jr. Heat Mass Transfer, Vol. 36, pp. 507-517 (1993).

[7] Karwa, R., 2003, “ Experimental Studies of Augmented Heat Transfer and Friction in Asymmetrically heated Rectangular Ducts with Ribs on the Heated Wall in Transverse, Inclined, V-Continuous and V-Discrete Pattern," Int. Comm. Heat Mass Transfer, Vol. 30, No. 2, pp. 241-250.

[8] Fluent 6.0 User's Guide Vol. 2.

[9] Tanda, G., " Heat transfer in rectangular channels with transverse and Vshaped broken ribs” Int. Jr. Heat Mass Transfer, Vol. 47 pp. 229-243, (2004).

[10] Davidson, Lars, 1997 “An Introduction to Turbulence models," Chalmers publication.

[11] 11.Versteeg, H.K., and Malalasekera, W., 1995, "An Introduction to Computational Fluid Dynamics”, Longman publication. 